\title{
Standing but not Delivering: Preparing Pre-service Teachers to use LGBTQ Young Adult Literature in the Secondary English Classroom
}

\author{
Paula Greathouse
}

TenNessee TeCH

\section{MIKE DiCCIO}

NORTHERN KENTUCKY UNIVERSITY

Despite calls from national organizations (CAEP, NCTE) to prepare teachers to include the study of LGTBQ culture into classrooms, little progress has been made incorporating LGTBQ themed literature and dialogue surrounding LGBTQ issues in secondary classrooms (Clark, 2010; Sieben \& Wallowitz, 2009; Haertling-Thein, 2013). To examine why, this qualitative case study explored the transition of two educators who participated in LGBTQ teacher training as teacher candidates from pre-service to practicing teachers. Consistent with current research, the researchers discovered that teacher training in LGBTQ literature and issues promoted an ally-stance. Participants came to recognize the need to include this genre within their curriculum as practicing teachers and made a commitment to do so. However, this stance was not enough to influence the actual use of LGBTQ literature and dialogue surrounding LGBTQ issues in the classroom. We discuss the factors that shape this resistance despite participants maintaining an ally-stance. We recommend a more widened scope of study of LGBTQ issues and literature within our English teacher education programs and added professional development of current practicing teachers and administrators in an effort to make explicit the literary value of LGBTQ themed texts and the responsibility for dialogue on LGBTQ issues to occur.

The Council for the Accreditation of Educator Preparation (CAEP) diversity proficiency standards in teacher education requires education programs to prepare teacher candidates to "incorporate multiple perspectives in content" (p. 21), which includes lesbian, gay, bisexual, transgender and/or questioning (LGBTQ) perspectives. According to Interstate 
Teacher Assessment and Support Consortium (InTASC) model core teaching standards, this CAEP standard specifically calls for the teacher to "facilitate learners ability to develop diverse social and cultural perspectives that expand their understanding of local and global issues and create novel approaches to solving problems” (p. 5). In 2007, The National Council for Teachers of English (NCTE) published a position statement entitled "Resolution on Strengthening Teacher Knowledge of Lesbian, Gay, Bisexual, and Transgender Issues,” which also called for the study of LGBTQ issues within English teacher education programs. It was the intention of this resolution to educate teachers about LGBTQ issues and prepare them to teach with LGBTQ-themed texts in order to increase the visibility and recognition of this culture within English classrooms. In their efforts to fulfill the CAEP standard requirement and heeding NCTE's resolution, English teacher education programs first had to determine where to place the study of LGTBQ literature and issues within their program and, second, had to decide how to prepare teacher candidates in a way that would lead to the inclusion of multicultural and global perspectives through an LGBTQ lens in the classroom. When referencing LGBTQ culture and perspectives, this preparation would lend itself to ally-work in the classroom. Ally-work, as defined by Clark (2010) and adopted for this study, moves beyond interrupting racist, heterosexist and homophobic discourses; rather, ally-work invites critical dialogue and discussion, interrogating perceived lines of difference and inquiring into the possibilities for creating productive alliances across these lines (p. 705).

It has been almost a decade since NCTE's position statement was released, and little, if any, progress has been made in the implementation and study of LGBTQ literature and issues in secondary English classrooms notwithstanding the efforts of some secondary English education programs and the ally-stances adopted by teacher candidates within these programs (Clark, 2010; Sieben \& Wallowitz, 2009; Haertling-Thein, 2013). The authors wondered: as secondary English language arts teacher educators, where are we falling short?

In a large urban research university in the southeast, the secondary English language arts (ELA) teacher education program requires all secondary English education teacher candidates to take an adolescent literature course. Within this course, several weeks are devoted to the study of issues that surround LGBTQ adolescents within schools and the 
teaching of LGBTQ themed young adult (YA) literature. The intention is to not only acquaint pre-service or in-service teachers with adolescent literature as a genre worth attention, but to also guide them in the integration of this genre within thematic units of study. Specific to LGBTQ issues, the objective is for students to develop an awareness and understanding of LGBTQ culture through the study of cultural values and ethics found in LGBTQ YA literature and to introduce them to a literacy framework through which to approach the reading and discussion of these texts. In other words, we propose to educate students in LGBTQ issues and acquaint them with LGBTQ YA literature in a way that would encourage ally-work in their future language arts classrooms.

The research is replete with studies regarding teacher candidate's beliefs and attitudes towards the use of LGBTQ literature and discussion of LGBTQ issues and the forces behind its resistance (Clark, 2010; Haertling-Thein, 2013; Hermann-Wilmarth, 2010; Malo-Juvera, 2015; Puchner \& Klein, 2011). There is also evidence that supports the notion that teacher candidates adopt an ally-stance as a result of the study of LGBTQ issues and literature in teacher preparation courses (Clark, 2010; Hermann-Wilmarth, 2010). But what happens when teacher candidates become teachers? Does the adopted allystance lead to ally-work in the classroom?

Research on first-year and novice teacher experiences refers to the first three years of teaching as a "sink or swim” period (Feiman-Nenser, 2001; Hill, 2004; Lundeen, 2004; Winstead Fry, 2007). Most first-year and novice teachers tend to implement traditional teaching methods, usually the ones they experienced in their own schooling, "instead of utilizing the innovative ones they were exposed to in teacher preparation" (Winstead Fry, 2007, 216) in order to survive in the classroom. Feiman-Nenser (2001) posit these educators often "stick to whatever practices enable them to survive whether or not they represent 'best' practice in that situation” (1014). Goodwin (2012) postulate these practices stem from several challenges new educators face regarding classroom management, curriculum freedom, and unsupportive environments. The fear that stems from these challenges include fear of student and parental confrontation, evaluations, teaching expectations, inadequate preparation, student academic success, and time utilization (Wilson, Ireton \& Wood, 1997). Given these challenges and fears, first-year and novice teachers tendencies to lean towards the traditional cannon, which includes few 
LGTBQ-themed works during their "rookie" years may stifle the inclusion of LGBTQ literature, despite their enthusiasm and belief in the need to include this genre and dialogue. As teacher educators who have experienced the importance of including LGBTQ themed literature and dialogue on LGBTQ issues in our own classrooms, we are left wondering if the preparation we are providing is strong enough to endure the challenges and fears faced by first-year and novice teachers. In other words, is the ally-stance that forms in teacher preparation programs strong enough to overcome the challenges and fears first-year and novice teachers face?

There is a paucity of research available that examines the transference of an allystance adopted in a teacher preparation program to first-year teachers' classrooms. Furthermore, few studies have examined the relationship between curriculum and/or pedagogical beliefs in teacher preparation programs and curriculum and/or pedagogical beliefs of practicing teachers that may or may not lead to ally-work in the classroom.

This qualitative case study followed two secondary English language arts teacher candidates as they transitioned from students to teachers in an effort to explore their beliefs and experiences with LGBTQ YA literature in their course preparation and in their curriculum as a practicing teacher. Qualitative case studies aim to provide a "thick description" of a particular phenomenon to fully describe the experience (Stake, 1995). By exploring the beliefs and experiences of these teacher candidates transitioning into teaching, the researchers hoped to gain an understanding of the relationship between the teacher preparation course, which included the study of LGBTQ issues and young adult literature, and the teacher candidate's inclusion or exclusion of LGBTQ young adult literature and dialogue in their secondary classrooms as practicing teachers. Our guiding questions for this study were:

1. What are teacher candidates, who have had education on LGBTQ teacher training, beliefs about including LGBTQ young adult literature after being in the classroom for a year?

2. How do teacher candidates describe their experience with LGBTQ young adult literature as first-year practicing teachers in their current curriculum? 


\section{METHODS}

\section{CONTEXT}

The University. The university serves nearly 48,000 students with the College of Education serving nearly 2,500 students. The university hosts a number of multicultural student organizations, including PRIDE Alliance. A yearly award for educators serving the LGBTQ community is given by the PRIDE Alliance, which was awarded to the first author. Further the university offers an LGBTQ+ diversity training for students and staff, an intercultural student leadership conference which promotes cultural awareness of underrepresented groups, and hosts an annual LGBTQ history month.

\section{THE PROGRAM}

The goal of the adolescent literature course was to guide students in developing an awareness and understanding of LGBTQ culture through the study of cultural values and ethics found in LGBTQ young adult literature. While students in the program take general diversity courses, such as a multicultural and adolescent development course, this YA course is the only course that has a specific focus on LGBTQ issues in the classroom.

\section{THE UNIT OF STUDY}

The premise of the LGBTQ unit of study within the adolescent literature course was framed on the belief that LGBTQ young adult literature can be a valuable instrument for all students, where each can discover their own beliefs, values, gender expressions and identities, while simultaneously addressing social injustices and misconceptions that surround each. The unit begins with an examination of students' frames of reference regarding culture, gender, and sexuality and in an effort to identify potential biases within these frames. The intention of this activity is for students to recognize, discuss, and reflect on their personal beliefs and perceptions about those who may express identities outside of their own identities. Transitioning from self to the adolescent student, participants examine current GLSEN statistics in an effort to acquaint themselves with the everyday school experiences of adolescents who identify as LGBTQ. Using the GLSEN survey findings, course members are placed within teams and charged with the creation of a bibliography that includes relevant and current facts that would be useful for a middle or secondary 
teacher. Additionally, this bibliography calls for the inclusion of information regarding where a student can call and/or write for help if they experience bullying or harassment as a result of identifying as LGBTQ. Once the project is complete, students are introduced to Queer Theory, a critical approach to reading LGBTQ YA literature. The purpose of framing the examination of these texts through this theory draws on the notion that this approach allows students to critically examine the issues of gender identity and sexual orientation in literary texts. The culminating task for this unit asks students to connect theory to practice. Students begin this task by reading an LGBTQ themed YA novel. They are given suggestions, but are not limited to the following: Annie on My Mind (Garden, 2007), Becoming Chloe (Ryan Hyde, 2008), Shine (Myracle, 2011) and The Drowning of Stephen Jones (Green,2012). After reading their chosen novel, students are charged with the creation of lesson plans for the study of their text. Within these plans, students are required to demonstrate their ability to engage adolescents in socially responsible dialogues about gender expressions, sexual identities and LGBTQ issues as presented within the novel.

\section{PARTICIPANTS}

Using purposeful convenience sampling, all 24 students enrolled in an adolescent literature teacher preparation course at a large urban research university in the southeast in spring of 2013 were asked to participate. All students enrolled in the course were secondary ELA teacher candidates in their junior or senior years. This population provided an ideal sample to discuss the aims of this study as teacher candidates would be discussing the inclusion of LGTBQ literature in the secondary ELA curriculum and would be soon transitioning to beginning teachers. Of the 24 possible members, only two consented to take part in the study. Therefore, participants in this study consisted of two teacher candidates who transition into beginning teachers over the course of a year.

Both participants are in their early 20's and are currently secondary ELA teachers in urban secondary schools in the southeast. Neither school houses a Gay Straight Alliance Club. Both schools do have a bullying policy in place that includes a focus on students who identify as LGBTQ, however, only one specifically requires students to read and sign. This school also offers a link on its home page for students to anonymously report any instances 
of bullying they have witnessed or experienced. Within their own classrooms, each participant shared that they teach several openly gay students and felt there were several others who identified as LGBTQ but had not personally disclosed this information to them. Additionally, both participants indicated that as first-year teachers they had little support from administration and colleagues and felt that the school communities in which they teach were not truly tolerant towards the LGBTQ culture or students who identified as LGBTQ.

\section{DATA COLLECTION}

This study was conducted using a structured interview. The interview questions focused on general beliefs and attitudes about the use of LGBTQ adolescent literature in the secondary English class. The open-ended questions focused on the participant's experiences with LGBTQ literature in their secondary and post secondary schooling and explored their current beliefs about the use of this genre in the secondary classroom as preservice teachers. For example, question one asked participants "what experiences have you had with LGBTQ literature in your secondary and post secondary courses?” while another asked “what are your beliefs about using LGBTQ literature in the classroom?” Interview questions were presented to the participants while members in the adolescent literature teacher preparation course through an on-line reflective course assignment.

Once each participant finished their first full year of teaching, a follow-up semistructured interview was conducted through email. Participants were asked to answer the same questions posed during the initial interview. In addition to these questions, participants were also prompted to share how they incorporate LGBTQ literature in the curriculum. Probing questions were used to elicit further responses. Participants willingly added commentary regarding the intersection of their beliefs and literature choices within their curriculum during their first year in the classroom.

Given the research on the challenges and fears that first year teachers face, it is suggested that as teachers move from novices to veterans, the tendency to become more innovative in their instruction arises. As such, we plan to conduct follow-up interviews with participants after their second, third and fourth full year of teaching. 


\section{DATA ANALYSIS}

Data consisted of participant responses from both interviews. Responses were analyzed using open coding and constant comparison. During the open coding process data are separated to create concepts or terms that represent small blocks of data (Corbin \& Strauss, 2008). Constant comparison consists of comparing data from two segments of data to look for similarities and differences in order to determine trends in the data (Corbin \& Strauss, 2008). Responses were first read holistically to gain familiarity with the data. Both authors coded responses individually and then collaboratively identified and defined emerging themes. Member checks were conducted to triangulate the data and all participants informed researchers that data and descriptions were accurate representations of their perceptions and perspectives.

\section{FINDINGS}

Two major themes were identified in the data: 1) an adopted and sustained ally stance and 2) resistance of ally-work despite this ally-stance. Participants shared that their adoption of an ally-stance was a direct influence of their exposure to and manipulation of LGBTQ literature and discourse on LGBTQ issues within the adolescent literature course. As they transitioned to practicing teachers, this stance was sustained. Experiences within both their school and classroom contexts added to their belief that the study LGBTQ literature and issues was necessary. However, data also revealed that this stance was not enough to support ally-work within their classrooms. Resistance data revealed one major theme: fear. Fear of administrative repercussion, community backlash, and student responses was so great that both participants felt it easier not to include the study of LGBTQ literature or issues in order to avoid potential complications that may arise from this study within their own classrooms.

\section{AN ALLY-STANCE ADOPTED AND SUSTAINED}

As teacher candidates, both participants shared that they had no exposure to adolescent LGBTQ literature and little, if any, involvement in dialogue on LGBTQ issues within their own secondary schooling experiences. Sue (a pseudonym) expressed "If there was any semblance... there was no spotlight put upon the topic. Even the films that we were given 
to see did not have any characters that were LGBTQ” when discussing her own high school English class experiences. Chris (also a pseudonym) shared his secondary experiences in English stating "there was a shortage of books or texts wherein the main characters were LGBTQ and dealing with issues related to identifying as such.” However, he added conversations about LGBTQ culture and issues did occur on several occasions, but only when discussing Walt Whitman and Shakespeare’s Sonnets.

\section{CREATING A CLIMATE OF INCLUSION}

Even with limited familiarity, both Sue and Chris adopted an ally-stance as a result of participation in the adolescent literature course. Both participants shared similar perspectives about the importance of recognizing this culture within their future classrooms. Sue shared that through the adolescent literature course she came to believe that all cultures should be recognized and valued within classrooms as “accepting, encouraging and incorporating these differences in the classrooms helps especially with class building.” Her mission in reaching LGBTQ students in her future classroom was to include the study of LGBTQ adolescent literature to show those who identify as lesbian, gay, bisexual, and/or transgender that they are "not alone and that there is hope and life beyond what may seem like insurmountable boundaries now.” At the end of the course, Chris posits that "we have as much responsibility to use LGBTQ literature in the classroom as we do to use works by female, black, and all other types.” He made a commitment to include texts that contain LGBTQ characters and encourage dialogue about LGBTQ issues within his future classroom.

As they transitioned into practicing teachers, participants’ beliefs were not only sustained, but were further strengthened through their experiences within their own classroom. Sue disclosed she felt it "unfair to cover such genres as African-American, Latino-American, or women's literature, and not give equal consideration to LGBTQ literature.” Additionally, she felt that her LGBTQ students needed authentic experiences and the inclusion of LGBTQ adolescent literature might offer them this opportunity. Chris coupled Sue's perspective and added that he felt through the inclusion of LGBTQ adolescent literature, students are offered windows into the LGBTQ community which “encourages insight rather than discouraging information.” Through the use of LGBTQ 
adolescent literature and dialogue on LGBTQ issues, Chris believed these inclusions would foster a "safe and secure learning environment" for all students and as such, needed to occur within every classroom in every school.

These newly extended beliefs continued to affirm the participants' stance that all students should be free to read literature that incudes LGBTQ characters and discuss issues surrounding sexual orientation because these media can serve as an access point for those who have identified as lesbian, gay, bisexual or transgendered, or are questioning their sexuality and as a cultural connector for all students. Sue not only argued "every student no matter their gender, sexuality, culture, economic status, etc., should be free to read and report on their thoughts in the classroom no matter what characters are being displayed within the pages of the book that they read” but further claimed that teachers should "...not deny a student the opportunity to read a book that will help them even if a character is LGTBQ." As an educator, Chris believed that even though he "may not personally identify with the experiences of characters in a novel, this does not mean that reading of the same text would not create a life-changing experience for one of my students.”

Despite limited time devoted to the study of LGBTQ adolescent literature and issues, the activities within the required course added new learning dimensions for each participant. Through their undertakings, an understanding of LGBTQ culture, its members and issues emerged which resulted in a self-reported adoption of an ally-stance. Sue cited statistics regarding LGBTQ adolescent experiences in the classroom as the primary need for inclusion, while Chris shared that "truly being a multicultural teacher meant you must include this genre in your curriculum.” These teacher candidates made it clear that all ELA classrooms had an obligation to incorporate this genre of literature and dialogue about LGBTQ issues, not just for those that identified as LGBTQ but for all students.

Futhermore, through a gender criticism approach, to reading LGBTQ literature one that examines the construction of gender and sexuality within literary texts, participants reported feeling more comfortable in their ability to one day include the study and dialogue of LGBTQ issues and literature in their own classrooms. The study of this approach provided participants with not only definitions of queer terminology, but also a framework to guide their own students through examinations of complexities that surround gender identity, gender expression, transgender issues and sexual orientation as presented within 
LGBTQ themed texts. Participants applied this approach to their own reading of LGBTQ texts within the course as they discussed ways in which LGBTQ texts can be vehicles through which adolescent students can challenge gender roles, expectations and norms. Through this activity, participants shared the potential LGBTQ texts have in not only shaping and informing their own beliefs, but the potential to shape and inform their students' beliefs as this approach helps highlight “share[ed] common experiences” and “insight” into the social construction of gender and sexuality.

\section{LGBTQ LITERATURE: ACCESS POINT AND CULTURAL CONNECTOR}

When asked to discuss their belief on the use of LGBTQ adolescent literature in the classroom during the follow-up interview, Chris posed the question,

"In a time when bullying truly is a raging bull within our schools and more and more students are turning to suicide as a means to be free from the confusion and hurt, why should we deny students something that will help them?”

Both participants argued the use of LGBTQ literature can become a valuable instrument for all students, as each is discovering their own sexual identities, while simultaneously being asked to address social injustices and misconceptions that surround the issue of sexual orientation. In this sense, the participants advocate there is a need to include LGBTQ literature in the secondary classroom as this genre can serve as an access point for those students who identify as LGBTQ. According to Sue, the secondary classroom was seen as "the ideal time to use LGTBQ literature in the classroom as students decipher who they are and look for those that share common experiences.” Furthermore, using LGBTQ literature as an access point not only affords those students who identify as LGBTQ to "see" himself or herself, but through the reading of LGBTQ adolescent literature in the curriculum Chris adds that "each student can connect with the content of a course" simultaneously. In other words, in addition to reading LGBTQ literature through a connection lens, teachers can also explore the authorial constructions of LGBTQ issues presented within.

Because adolescent literature often teaches us about the importance of understanding those who are different from ourselves, reading this genre holds the potential to provoke empathy (Glasgow, 2001; Kidd \& Castano, 2013; Wolk, 2009). As such, the 
introduction of LGBTQ adolescent literature in the secondary classroom extends beyond an access point for those who identify as LGBTQ. Sue suggests the use of LGBTQ adolescent literature in the secondary classroom "is also important for students who may not identify as LGTBQ as it builds empathy and exposes them to a culture that most have not had any interaction with.” Chris shared that through the use of LGBTQ adolescent literature and dialogue on LGBTQ issues, students who have identified as heterosexual "will be able to better understand what an LGTBQ student goes through if they are exposed to books that give them insight." The use of LGBTQ literature in this way affords educators opportunities to uncover misconceptions and hidden assumptions their students may have about the LGBTQ culture. But was this newly adopted and sustained ally-stance enough to influence ally-work within their own curriculum as newly practicing teachers?

\section{RESISTING ALLY-WORK DESPITE AN ALLY-STANCE}

As aforementioned, for both participants, this was the first encounter they had with this literary genre or theoretical approach. Their experience was limited, yet it was enough to influence the adoption of an ally-stance. As they transitioned into practicing teachers, this stance was not only sustained, but it was also affirmed as a direct result of their own classroom experiences. Unfortunately, while participants identified as having an allystance, they did not incorporate LGTBQ literature in their own classrooms.

When asked why, both participants shared that it was a direct result of fear.

\section{THE POWER OF FEAR}

Participants had a number of fears that kept them from incorporating LGTBQ literature. Those fears included being “caught” not adhering to their scripted curriculums, community backlash, and student responses. While both participants recognized the need to include LGTBQ literature ultimately these fears led to the decision to not include LGBTQ adolescent literature or the dialogue on LGBTQ issues in their curriculum.

New teachers are acclimating themselves to school cultures, discovering the nuances of teaching that could not be taught in a college classroom and seeking validation and approval in their instructional approaches from mentors and administration (Fantilli \& McDougall, 2009). In other words, new teachers are looking to make sure they are "doing 
it right” according to district, school, and administrative expectations. When asked to share their experiences with LGBTQ issues and adolescent literature in their own classrooms, whether it was assumed or explicitly stated by administration, participations expressed their biggest fear was that administration would not approve. Chris has an immense fear of administrator disapproval as a new teacher that even conducting a "mini-lesson on LGBTQ issues might be frowned upon during a pop-in evaluation.” Sue worried about possibly being caught not following her scripted curriculum as motive to "keep to the literature suggested by the curriculum maps for the ease of team planning and for the sake of not 'rocking the boat' excessively as a newcomer."

Community demographics such as socioeconomic, ethnicity, and religiosity often influence the instructional norms expected in schools (Coleman, Campbell, Hobson, McPartland, Mood, Weinfeld \& York, 1966). When positioned in a community context that does not celebrate diversity or one that is driven by religious influences, finding a place for the study of LGBTQ issues and adolescent literature became a task that neither participant was willing to undertake. Sue stated, "I teach in a particularly conservative community where being different is not always looked upon favorable...Thus, there are a great many who would likely object to the use of literature that is entirely LGTBQ-based.” Both participants also shared a fear of possible community backlash, specifically where the home school partnership was concerned. Despite the recognition by both participants that this genre can act as a cultural connector, Chris shared, “Teaching is much facilitated when there is a solid home partnership, so the fear of losing such a partnership is probably a driving factor” in my decision to exclude LGBTQ adolescent literature and issues from my instruction, making the risk of including this genre out weigh the benefits.

Discussions that arise as a result of reading texts "can enhance student understanding of content, broaden student perspectives, highlight opposing viewpoints, reinforce knowledge, build confidence, and support community in learning” (Blount \& Napolitano, 2014, p. 1). However, when considering the inclusion of LGBTQ adolescent literature and the discussion that may arise from the study of this genre had both participants concerned. Chris suggested, “The spontaneity of student generated questions can be scary.” Sue added "there’s the fear that one of my students will offend another child by laughing at them....thus, bullying issues might arise.” While some attempt was made 
by both participants to include some dialogue on LGBTQ issues in relationship to texts they were reading, Chris found that "students are generally unreceptive to discussion of these aspects of the text and tend towards stereotypes.” He pointed out that "students' already often "use the term "gay" to replace "lame” or "dumb” in the classroom, and sadly "faggot” carries a similar connotation." For Sue, it was easier not to continue the conversation that arose in fear of "being accused of saying something that could be misconstrued" than to address the homophobic nature of the language or the homophobic perspectives of the students. The participants' ally stance faltered due to challenges from administrators and students.

\section{DisCUSSION}

Instructional decision-making is often influenced by what schools, districts and communities constitute acceptable instructional norms. But what if a teacher discovers that these norms collide with their beliefs on what needs to be studied and discussed, especially when it comes to LGBTQ literature? How do teachers negotiate these beliefs within contexts that do not support the study of LGBTQ literature and the discussions that arise from these explorations?

Our findings support the literature on pre-service teacher's adoption of ally-stances within teacher education programs as a direct result of the study of LGBTQ literature and issues. Our participants do not need to be convinced that LGBTQ texts and issues are important and should be included within classroom dialogues. However, the challenges and fears our participants faced as first-year teachers were prime motivators for excluding LGTBQ texts and discussions on LGBTQ issues in their classrooms despite these perspectives. Even with exposure to LGBTQ YA literature and a theoretical framework through which to read this genre, our university was missing a very important component. While these participants teacher education program included the study of LGTBQ literature and instructional ideas for incorporating this genre within their curriculum, the ways in which they may negotiate first-year fears and challenges, resistant parents, administrators, and other stakeholders when questioned or challenged in their decision to include LGBTQ literature and dialogue on LGBTQ issues were not addressed. These participants seemed to need instruction on how to make explicit the literary value of YA LGTBQ themed texts 
and the responsibility for dialogue on LGBTQ issues to occur to within their classrooms. In other words, they need support in including LGBTQ themed texts and discourse on LGBTQ issues from administrators and/or fellow colleagues. As such, we recommend a more widened scope of study of LGBTQ issues and literature within our educational leadership and English teacher education programs today in an effort to address these factors. As Bedford (2002) states:

Since prejudice against lesbians, bisexuals, and gays, along with the belief in the superiority of heterosexuality, are learned attitudes and cultural constructions, teacher education lies at the heart of combating homophobia and heterosexism and faces the challenge of breaking the culture of silence. (p. 134)

\section{FUTURE DIRECTIONS}

To address our recommendations, we suggest the inclusion of LGBTQ issues and literature throughout English education programs. Literature on LGBTQ issues should be included in multicultural literature, adolescent development, and social justice courses. Further, LGBTQ culture and literature should be infused within pedagogy, methods, and practicum coursework in the English education program. The hope is to not teach LGBTQ in isolation, but make it an accepted topic in all coursework throughout the program. LGBTQ instruction should include knowledge of the culture, literature (including young adult literature), and how to teach LGBTQ topics/concepts.

The participants sharing of their first-year experiences and challenges in relationship to their decision to exclude LGBTQ literature and dialogue on LGBTQ issues in their classrooms despite an ally-stance suggest a need for support and resources for veteran teachers and administrators. Professional development on LGBTQ issues which should include teaching professional organizational support (e.g. GLSEN, NCTE Gay Straight Educational Advisory) could be beneficial in assisting educators in their recognition of the LGBTQ culture within their current courses of study.

This study examined two teacher candidates' experiences concerning the use of LGTQB young adult literature in a secondary English classroom. While the data was limited to two responses, this study highlights the need for further research on developing an ally-stance within teacher education programs and how ally-stance teachers incorporate 
LGTBQ issues and literature in their classes. Additionally, given the research on first-year and novice teachers adoption of traditional methods due to challenges and fears faced within their first three years of teaching, a follow-up inquiry is warranted to determine if and when the ally-stance adopted within teacher preparation programs comes to fruition and the forces behind its manifestation. For English classrooms which "embrace lesbian and gay readers and readings would serve all students - those who are lesbian and gay themselves, those who other differences which go unrecognized, and those who lack sensitivity to difference” (Reese, 2000, p. 167).

\section{REFERENCES}

Bedford, T. (2002). Queer developments in teacher education: Addressing sexual diversity, homophobia, and heterosexism. In R. M. Kissen (Ed.), Getting ready for Benjamin: Preparing teachers for sexual diversity in the classroom (pp. 1331142). Lanham, MD: Rowman \& Littlefield Publishers.

Blount, J. M., \& Napolitano, R. (2014). Leading Classroom Discussion, Center for Excellence in Learning and Teaching, Iowa State University, retrieved from: http://goo.gl/cCCZaS.

Clark, C. (2010). Preparing LGBTQ-allies and combating homophobia in a U.S. teacher education program. Teaching and Teacher Education, 26(3), 704-713.

Coleman, J., Campbell, E., Hobson, C., McPartland, J., Mood, A., Weinfeld, F., \& York, R. (1966). Equality of educational opportunity (OE-38001). Washington, D.C.: Government Printing Office. Retrieved from http://files.eric.ed.gov/fulltext/ED012275.pdf.

Corbin, J., \& Strauss, A. (2008). Basics of qualitative research ( $3^{\text {rd }}$ ed.). Thousand Oaks, CA: Sage.

Council for the Accreditation of Educator Preparation (CAEP). (2013). The CAEP Standards. Retrieved on January 8, 2016 from http://caepnet.org/standards. Council of Chief State School Officers. (2011). Interstate Teacher Assessment and Support Consortium (InTASC) Model Core Teaching Standards. Retrived from http://www.ccsso.org/Resources.html on January 8, 2016.

Garden, N. (2007). Annie on my mind. New York, NY: Square Fish Books. 
Goodwin, B. (2012). Research Says New Teachers Face Three Common Challenges Educational Leadership, 69(8), 84-85.

Greene, B. (2012). The Drowning of Stephan Jones. Boston, MA: Greene and Sandell.

Glasgow,J. (2001). Teaching Social Justice through Young Adult Literature. The English Journal, 90(6), 54-61.

Kidd, D. \& Castano, E. (2013). Reading Literary Fiction Improves Theory of Mind. Science, 342(6156), 377-380.

Kitchen, J. \& Bellini, C. (2013). Gay-Straight Alliances: Making Ontario Schools Safe and Inclusive. Teaching and Learning, 7(3), 62-75.

Fantilli, R. and McDougall, D. (2009). A study of novice teachers: challenges and supports in the first years. Teaching and Teacher Education 25(6), 814-825.

Haertling Thein, A. (2013). Language Arts Teachers' Resistance to Teaching LGBT Literature and Issues. Language Arts, 90(3), 169 -180.

Hermann-Wilmarth, J. (2007). Full inclusion: Understanding the role of gay and lesbian texts and films in teacher education classrooms. Language Arts, 84(4), 347-356.

Hill, J. (2004). Five years later. Journal of Education, 185(1), 77-82.

Lundeen, C. A. (2004). Teacher development: The struggle of beginning teachers in creating moral (caring) classroom environments. Early Child Development and Care, 174(6), 549-564.

Malo-Juevera, V. (2015). A Mixed Methods Study of Pre-service Teachers’ Attitudes toward LGBTQ Themed Literature. Study and Scrutiny: Research on Young Adult Literature, 1(1), 1-45.

Myracle, L. (2011). Shine. New York, NY: Amulet Books.

NCTE. (2007). Resolution on strengthening teacher knowledge of lesbian, gay, bisexual, and transgender (LGBT) issues. Retrieved on August 10, 2015 from http://www.ncte.org/ positions/statements/teacherknowledgelgbt.

Puchner, L., \& Klein, N. (2011). The right time and place? Middle school language arts teachers talk about not talking about sexual orientation. Equity \& Excellence in Education, 44(2), 233-248. 
Reese, J. (2000). Creating a Place for Lesbian and Gay Readings in Secondary English Classrooms. Lesbian and Gay Studies and the Teaching of English: Positions, Pedagogies and Cultural Politics. Ed. Spurlin, W. National Council of Teachers of English: Urbana, Il.

Ryan Hyde, C. (2008). Becoming Chloe. New York, NY: Knopf Books for Young Readers.

Sieben, N., \& Wallowitz, L. (2009). "Watch what you teach": A first-year teacher refuses to play it safe. English Journal, 98(4),44-49.

Stake, R. E. (1995). The art of case study research. Thousand Oaks, CA: SAGE Publications.

Wilson, B., Ireton, E. \&Wood, J. (1997). Beginning teacher fears. Education, 117(3), 395-396.

Winstead Fry, S. (2007). First-Year Teachers and Induction Support: Ups, Downs, and In-Betweens. The Qualitative Report 12(2), 216-237.

Wolk, S. (2009). Reading for a better world: Teaching for social responsibility with young adult literature. Journal of Adolescent and Adult Literacy, 52(8), 664-673.

Paula GREATHOUSE is an assistant professor of English Education at Tennessee Tech and former secondary language arts and reading teacher. She is the recipient of the 2012 NCTE High School Teacher of Excellence Award. Her interests include adolescent literacy, young adult literature, and a positive youth development approach to reading.

MIKE DICCIO is an assistant professor of Literacy Education at Northern Kentucky University and former middle school language arts and reading teacher. His interests include using the arts to teaching reading at the middle level, middle level teacher preparation, and arts-based qualitative research. 